\title{
Synthetic Brain Tumor Peptides-Pulsed Autologous Dendritic Cell Vaccine
}

National Cancer Institute

\section{Source}

National Cancer Institute. Synthetic Brain Tumor Peptides-Pulsed Autologous Dendritic

Cell Vaccine. NCI Thesaurus. Code C74079.

A cell-based cancer vaccine composed of autologous dendritic cells (DCs) pulsed with synthetic brain tumor peptides with potential immunostimulatory and antineoplastic activities. Upon administration, synthetic brain tumor peptides-pulsed autologous dendritic cell vaccine may stimulate anti-tumoral cytotoxic T lymphocyte $(C T L)$ land antibody responses ag ainst glioma tumor cells, resulting in glioma tumor cell lysis. 